\title{
XXVIII SEMINARIO INTERUNIVERSITARIO DE TEORÍA DE LA EDUCACIÓN
}

\author{
La Escuela hoy. La Teoría de la Educación en el proceso colectivo \\ de construcción del conocimiento
}

Universidad de Oviedo, 15 al 17 de noviembre de 2009

El seminario ha tenido por objeto mostrar las insuficiencias que presenta hoy el modelo que permitió alumbrar la Escuela y que aún pervive, así como apuntar una Teoría de la Educación que sirva de cimiento a una nueva escuela enraizada en la sociedad y que se muestre solvente en la respuesta a los desafíos del presente. Ha encarnado además una oportunidad de encuentro e intercambio entre profesores de todas las Universidades españolas que compartieron su preocupación no sólo por la Teoría de la Educación en particular sino también por la Pedagogía en general. Para alcanzar este objetivo general, el seminario se propuso los siguientes objetivos:

- Mostrar cómo, en los últimos años, los principales debates sociales que se han mantenido en torno a la Educación no son otra cosa que manifestaciones o síntomas del agotamiento de un modelo.

- Sentar las bases para la reconstrucción de una Teoría de la Educación capaz de sustentar un nuevo modelo educativo en que la fractura escuelasociedad sea superada.

- Señalar las líneas y contenidos del saber escolar hoy.

- Definir nuevas relaciones dialógicas educativas.

La inauguración del seminario tuvo lugar el día 16 de noviembre de 2009, corriendo a cargo del Ilmo. Sr. Consejero de Educación del Principado de Asturias y el Excmo. Sr. Rector de la Universidad de Oviedo. En ambos casos se insistió en la relevancia de la temática del seminario y la repercusión de los nuevos modelos de escuela y de educación en la sociedad del siglo XXI: en las sociedades modernas que pretenden avanzar hacia un modelo de Sociedad del Conocimiento no cabe sino plantearse una apuesta seria y decidida por la educación.

La primera ponencia, cuyo tema fue La escuela, en crisis, corrió a cargo de Gonzalo Vázquez Gómez, José Manuel Touriñán y Jaume Sarramona López. La segunda tuvo por título Reconstrucción del sentido de la actividad educativa escolar, siendo presentada por los profesores Ángel García del Dujo y Fernando Gil Cantero. Ya el martes, 17 de noviembre, se desarrolló la ponencia Tejiendo Vínculos. La textura de la relación educativa, a cargo de los profesores Clara Romero Pérez, Luis Núñez Cubero, Antonio Bernal Guerrero y Juan Ramón Jiménez Vicioso. 
Finalmente, los profesores Miquel Martínez, Gonzalo Jover Olmeda, Patricia Villamar Manero y Cruz Pérez asumieron la responsabilidad de presentar la cuarta ponencia del seminario cuyo tema fue El saber escolar.

La dinámica habitual de estos seminarios ya tradicionales en el ámbito de la educación hace que la combinación de las ponencias desarrolladas y de los debates posteriores permita complementar y revisar las opiniones vertidas en las ponencias/adendas y las exposiciones formales de los ponentes. En este caso, el interés de las ponencias suscitó intensos debates que se prolongaron durante el tiempo previsto en cada una de las sesiones al efecto. El elevado número de adendas presentadas para cada una de las ponencias viene a reforzar esta idea en relación al interés de la comunidad universitaria por los temas trabajados. Contribuye también a incentivar el debate que todos los asistentes dispusieran con antelación a la celebración del seminario de los textos de las ponencias y las adendas presentadas a cada una de ellas desde la página web del seminario: http://www. uniovi.es/site09/ de modo que sus reflexiones pudieran ser fruto de una lectura más detenida y en profundidad.

Como conclusión, puede decirse que la calidad de los trabajos presentados, la posterior exposición durante el seminario y muy especialmente la amplia discusión a partir de todo ello han sido enormemente enriquecedores para todos los asistentes y organizadores. 